\title{
Miniaturized Balanced Antenna with Integrated Balun for Practical LTE Applications
}

\author{
Issa ELFERGANI , Jonathan RODRIGUEZ ${ }^{1,2}$, Fathi ABDUSSALAM ${ }^{3}$, \\ Chan H SEE ${ }^{4}$, Read ABD-ALHAMEED ${ }^{3}$ \\ ${ }^{1}$ Instituto de Telecomunicações, Aveiro, Portugal \\ ${ }^{2}$ University of South Wales, Pontypridd, CF37 1DL, UK \\ ${ }^{3}$ Antennas \& Applied Electromagnetics Research Group, School of Engineering and Informatics, Univ. of Bradford, \\ Bradford, BD7 1DP, UK \\ ${ }^{4}$ School of Engineering, University of Bolton, Bolton, BL3 5AB, UK \\ i.t.e.elfergani@av.it.pt, jonathan@av.it.pt, \{r.a.a.abd,f.m.a.abdussalam\}@bradford.ac.uk, C.See@bolton.ac.uk \\ Submitted October 20, 2016 / Accepted December 20, 2016
}

\begin{abstract}
A design of dual-band balanced antenna structure operating in the 700 and $2600 \mathrm{MHz}$ LTE bands is studied and investigated. The overall dimensions of the radiator are $50 \times 18 \times 7 \mathrm{~mm}^{3}$ allowing it to be easily concealed within mobile handsets. A broad-band balun is designed and integrated with the antenna handset in order to provide the feeding network and perform the measurements of the antenna radiation performance. Prototypes of the proposed antenna with and without balun are fabricated and verified. The simulated and practical results with and without the handheld effects in terms of reflection coefficient, power gain and radiation pattern, are studied and show reasonable agreement.
\end{abstract}

\section{Keywords}

Balanced antenna, printed dipole, dual-band, LTE, balun

\section{Introduction}

The demand for researching and developing multisystem handset has increased rapidly in recent years. The design of a wireless transceiver in a smart phone or a portable device must support multi-system operations, since the forthcoming mobile networking ecosystem is expected to constitute legacy and future $5 \mathrm{G}$ technology. This raises numerous challenges and requirements for mobile phone antenna designers [1]. To combat these problems, antennas are required to be thin, light, compact design, reduced volume size, and low energy for better incorporating into a portable device. As a result, several works have recently been dedicated to internal multiband antennas in mobile handset applications. The planar Inverted-F antennas (PIFA) [2], [3], microstrip patch antennas [4], [5] and monopole printed structures [6], [7] have been considered as the most common internal mobile phone antennas. In particular, with the advancement of the LTE technology, smart phones are now broadly used, thus designing new antennas for legacy and future release of the LTE standard, catering for carrier aggregation and multiple wideband frequency bands are now of much interest in the research community. Numerous miniaturized LTE handset antennas have been reported [8-13].

By examining the work in [8-13], one can notice that, these antennas have only a single terminal and driven against a local ground plane. Having an antenna along with the system ground plane may help in improving the bandwidth and gain performance. These unbalanced antennas have been exploited in commercial handsets, especially as the mobile device is quite small. However, these unbalanced structures are sensitive to user hand held effect, in that the user's hand covers a large area of the antenna ground plane in which may change the impedance matching requirements of the antenna and it may lead in performance degradation. This is because the ground plane of such antennas is being used as part of the radiator structure in which a large amount of current would be induced on the radiator as well as on the antenna ground. As a result and while the device is being held by the users' hand, the coupling with the human hand/body, could degrade the antenna performance $[14,15,16]$.

To avoid such degradation performance phenomena, a balanced antenna is deemed as a promising candidate for the mobile phone since the current induced on the ground is small or approximately neglected, which leads to minor influences on the performances of the antenna in the scenario of device being held by the user's hand.

To exploit this beneficial property, a number of mobile phone balanced antenna structures operating in dualband, multiband and wide band have been recently studied [16-27]. Tab. 1 shows the differences between these antennas in terms of operating frequency band, antenna size, power gain and efficiency.

By investigating Tab. 1, one can observe these available balanced antennas can only cover either the major ex- 
isting mobile bands or/and UWB spectrum, for example: antenna design in [17] can only cover GSM900, the antenna geometry in [18] is capable to work for GSM1800, an antenna operating over the GSM900/1800 was proposed in [19]; whereas [16], [20] proposed antennas to operate in WLAN, authors in [22] proposed balanced antenna structure covering GSM and UMTS, while [23] designed a balanced antenna to operate in GSM and WLAN, and authors in [24] offered balanced antennas that work in the full operation of three mobile radio bands of GSM900/1800, PCS/1900 and UMTS/2200.

On the other hand, several works have been reported to operate over the UWB spectrum, e.g. authors in [25] have proposed an antenna design that operates in both lower bands of UWB from 2.36 to $2.56 \mathrm{GHz}$ and higher bands of UWB spectrum from 5.13 to $12 \mathrm{GHz}$. Furthermore, in [26], [27] Vivaldi balanced antennas covering the whole range of UWB from 3.1 to $10.6 \mathrm{GHz}$ have been designed and tested.

In contrast, due to the big demand for higher data rate as well as larger bandwidth in recent network of mobile communication, the new technology of the 4th generation namely long-term evolution (LTE) has been developed and newly released. However, none of these balanced antenna designs in [16], [27] have the capability to operate in the range of the lower LTE bands and in particular the lower band of $700 \mathrm{MHz}$. To address this, we propose a miniaturized printed folded dipole balanced antenna, which operates at dual-band frequency bands of LTE, i.e. 698 to $748 \mathrm{MHz}$ and 2500 to $2690 \mathrm{MHz}$, for a mobile communication device.

By compromising the bandwidth, antenna size and frequency bands, some approaches were proposed by previous author's works [18], [20-24] to enable wide-band

\begin{tabular}{|c|c|c|c|c|}
\hline Ref & $\begin{array}{c}\text { Operating } \\
\text { Frequency } \\
\text { Band } \\
\text { (GHz) }\end{array}$ & $\begin{array}{c}\text { Size mm } \\
\text { including } \\
\text { ground plane }\end{array}$ & $\begin{array}{c}\text { Peak } \\
\text { Gain } \\
\text { Range } \\
\text { (dBi) }\end{array}$ & $\begin{array}{c}\text { Radiation } \\
\text { efficiency } \\
\text { (\%) }\end{array}$ \\
\hline 16 & 2.4 & $118 \times 62.5 \times 0.8$ & $\mathrm{NaN}$ & 75.3 \\
\hline 17 & 0.9 & $100 \times 50 \times 10$ & $\mathrm{NaN}$ & $\mathrm{NaN}$ \\
\hline 18 & 1.8 & $120 \times 50 \times 12$ & 4 & $\mathrm{NaN}$ \\
\hline 19 & 0.9 and 1.8 & $100 \times 50 \times 6.6$ & $\mathrm{NaN}$ & \\
\hline 20 & $\begin{array}{c}2.48,5,4 \\
\text { and } 6.5\end{array}$ & $90 \times 40 \times 7$ & $3.5-5.2$ & $\mathrm{NaN}$ \\
\hline 22 & $\begin{array}{c}0.9,1.8 \\
\text { and } 2.2\end{array}$ & $120 \times 50 \times 9.5$ & $2.5-3.5$ & $\mathrm{NaN}$ \\
\hline 23 & $1.8-2.4$ & $120 \times 50 \times 9.5$ & $2.7-4.2$ & $70-94$ \\
\hline 25 & $\begin{array}{c}2.36-2.56 \\
\text { and } \\
5.13-12\end{array}$ & $87 \times 35 \times 1$ & $0.7-5$ & $\mathrm{NaN}$ \\
\hline 26 & $3.1-10.6$ & $32 \times 35 \times 1.6$ & $-3-5.25$ & $\mathrm{NaN}$ \\
\hline 27 & $3.1-10.6$ & $123.5 \times 96.7 \times 1.6$ & $\mathrm{NaN}$ & $\mathrm{NaN}$ \\
\hline proposed & $0.7-2.6$ & $100 \times 50 \times 7$ & $\begin{array}{c}0.95-1.7 \\
\text { and }\end{array}$ & $79-95$ \\
\hline
\end{tabular}

Tab. 1. Comparison of the performance of the published balanced antennas. and dual-band functional operation, as shown in Tab. 1. In comparison to [16], [27], this version of the proposed balanced antenna has come up with such advantage of covering the dual-band of LTE namely $700 / 2600 \mathrm{MHz}$ as well as achieving a size reduction compared to previous work in [16-18], [24, 25]. Moreover, this present antenna has achieved a better efficiency in contrast to [16], [23]. Furthermore, it accomplishes an improved gain compared with works in [18, 22, 23, 25, 26].

\section{Proposed Antenna Structure}

The full configuration of the present dual-band LTE mobile balanced design is shown in Fig. 1. The present design has a simple structure. The antenna is printed over a FR4 material permittivity of 4.4 , tangent loss of 0.025 and with a thickness of $1.6 \mathrm{~mm}$. The overall size of the antenna and handheld device is $100 \times 50 \times 7 \mathrm{~mm}^{3}$, where the antenna size is $50 \times 18 \times 1.6 \mathrm{~mm}^{3}$. A balanced voltage source was used to feed the proposed design. The folded printed arms have a uniform width of $1 \mathrm{~mm}$.

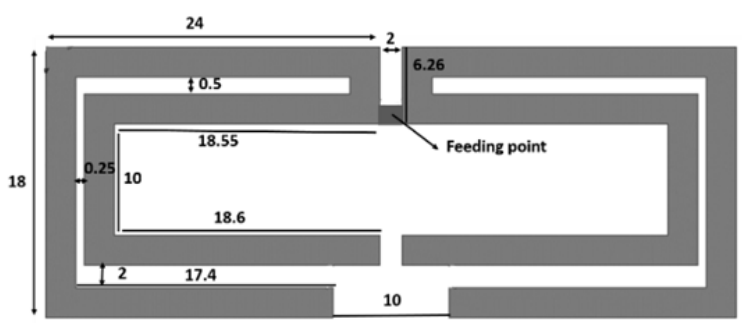

(a)

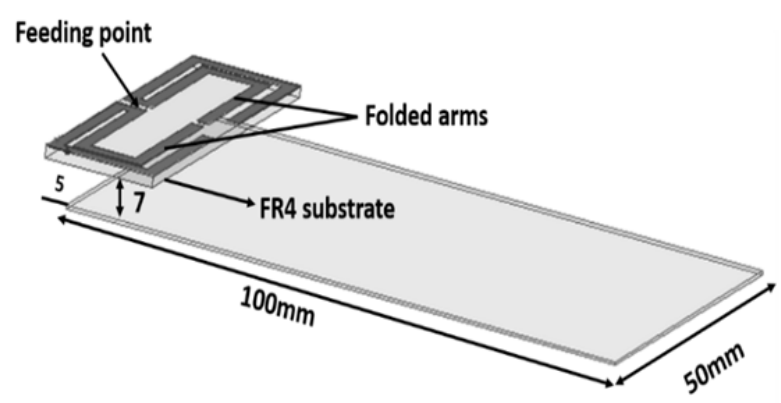

(b)

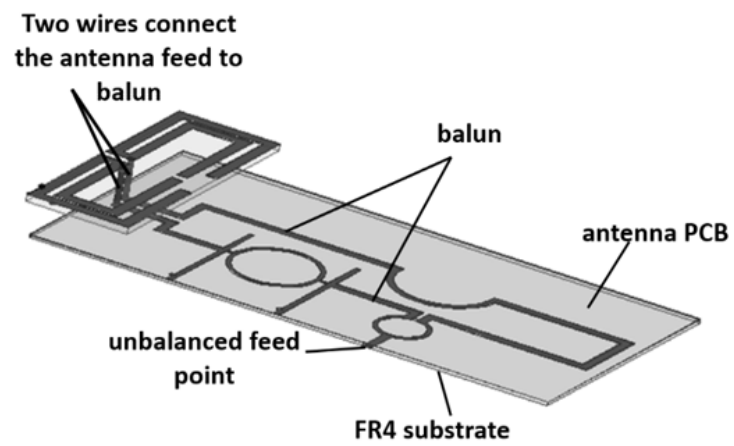

(c)

Fig. 1. Antenna structure: (a) Top view, (b) antenna without balun, (c) antenna with balun. Unit in $\mathrm{mm}$. 
The ground plane was shifted backward by $5 \mathrm{~mm}$. This has created a defected area under the radiator which has contributed to enhance and improve the bandwidth of the LTE lower frequency of $700 \mathrm{MHz}$. The proposed antenna comprises of two printed dipoles arms with separation slot of $2 \mathrm{~mm}$ width. Each dipole arm is patterned in a way to create two joint $U$ shapes. The formation of such printed dipole shapes has not only contributed towards the antenna miniaturization, but has also effectively achieved the dual-band LTE frequencies defined within this work in particular the lower band of $700 \mathrm{MHz}$. It should be noted that different set/shapes of folded arms were attempted on the top of the substrate in which it can pave the path towards the targeted dual-band frequencies of $700 / 2600 \mathrm{MHz}$.

To further understand the contribution of the printed folded arms technique in size miniaturization, different antenna designs with several printed folded arms shapes were modelled. In this analysis, four standard different printed arms including L-shaped, U-shaped, L-U shaped and $2 \mathrm{U}$ shaped were studied. The dimensions of $\mathrm{L}, \mathrm{U}$ and L-U shapes are depicted in Fig. 2, while the proposed structure of $2 \mathrm{U}$ shapes are already shown in Fig. 1. The variation of the printed folded arms against the response of $\mathrm{S}_{11}$ was investigated within this study as depicted in Fig. 2. The simulated $\mathrm{S}_{11}$ of L-shaped, U-shaped, L-U shaped and $2 \mathrm{U}$ shaped arms of the proposed antenna are shown in Fig. 2. As can be seen, by implementing L-shaped radiator on each arm, the proposed antenna can only operate at $4200 \mathrm{MHz}$, but, when the U-shape was applied, the current path length of the antenna will be changed in which it will force the antenna to operate at $3500 \mathrm{MHz}$. On the other hand, by joining $\mathrm{L}$ and $\mathrm{U}$ shapes together on each side of the radiator, the dual-band paradigm started taking a place for which the proposed antenna is being able to cover the dual-band of 1000/3400 MHz. However, by employing 2U shapes configuration on each arm, the present antenna was tuned to meet the targeted dual-band of $700 / 2600 \mathrm{MHz}$ proposed within this study.

Planar balun in [28] is used and integrated on the handset of the proposed antenna to support the balanced

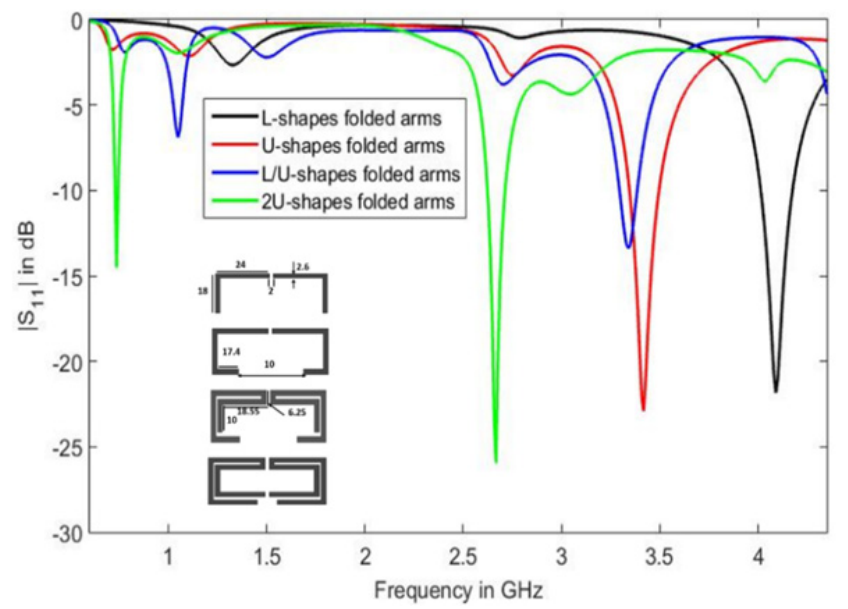

Fig. 2. The variation of the printed folded shapes against the response of $S_{11}$. feeding network, as illustrated in Fig. 1c. One can notice that the ground plane of the antenna was placed on one side of the FR4 dielectric with a thickness of $0.8 \mathrm{~mm}$, permittivity of 4.4 , and tangent loss of 0.025 , while the planar balun was located on the opposite side as depicted in Fig. 1c. The proposed antennas were modeled using HFSS software package [29]. The locations of two balanced ports of the balun were wisely designated to be exactly in direct position underneath the antenna feeding point on the upper sheet of the substrate. Dual thin cables were exploited in order to join the wide band balun to the antenna feeding point via holes. In this manner, the integration of both the antenna and its balanced feeding system were successfully accomplished. The proposed balun operates over a wider frequency range from $700 \mathrm{MHz}$ to $3200 \mathrm{MHz}$ in which the targeted frequency bands of 700 and $2600 \mathrm{MHz}$ proposed in this work can be easily met.

To further investigate the physical behavior of the antenna, the input impedance of the proposed antennas with and without balun in free space and hand held are studied and investigated as shown in Fig. 3. The values of the input impedance of the proposed antenna for the mentioned five cases were summarized in Tab. 2 .

As can be observed from Tab. 2, the proposed antenna for both free space and handheld scenarios exhibits a re-

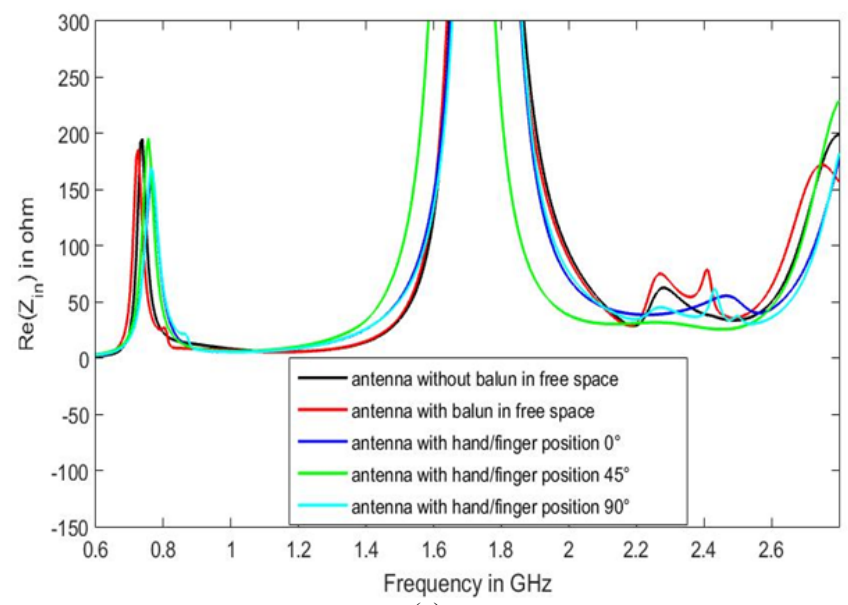

(a)

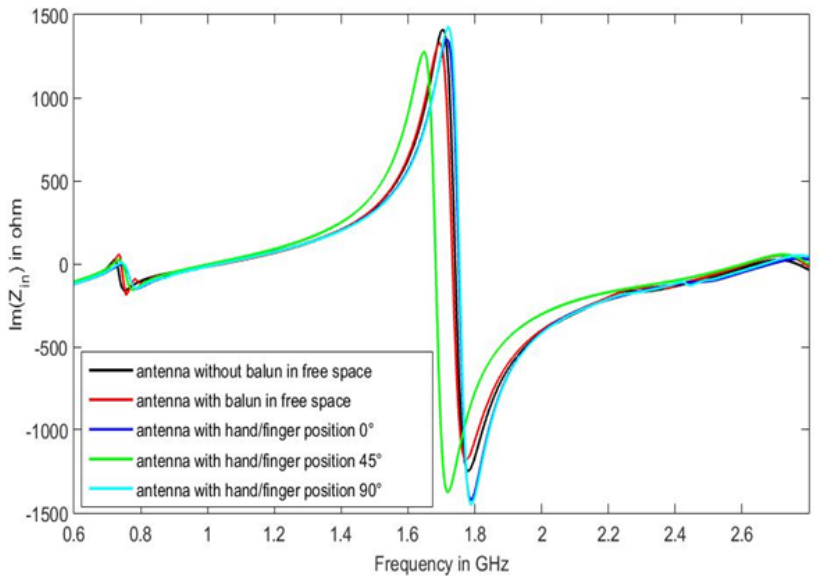

(b)

Fig. 3. Input impedance of the proposed antenna. 


\begin{tabular}{|c|c|c|c|c|c|}
\hline $\begin{array}{c}\text { Impedance } \\
(\boldsymbol{\Omega})\end{array}$ & $\begin{array}{c}\text { Antenna } \\
\text { without } \\
\text { balun } \\
\text { in free } \\
\text { space }\end{array}$ & $\begin{array}{c}\text { Antenna } \\
\text { with } \\
\text { balun } \\
\text { in free } \\
\text { space }\end{array}$ & $\begin{array}{c}\text { Antenna } \\
\text { with } \\
\text { finger } \\
\text { position } \\
\text { at 0 }\end{array}$ & $\begin{array}{c}\text { Antenna } \\
\text { with } \\
\text { finger } \\
\text { position } \\
\text { at 45 }\end{array}$ & $\begin{array}{c}\text { Antenna } \\
\text { with } \\
\text { finger } \\
\text { position } \\
\text { at 90 }\end{array}$ \\
\hline $\begin{array}{c}\text { Resistance } \\
700 \mathrm{MHz}\end{array}$ & 50 & 50 & 46 & 47 & 49 \\
\hline $\begin{array}{c}\text { Reactance } \\
700 \mathrm{MHz}\end{array}$ & 0 & 0 & -3 & -3 & -2 \\
\hline $\begin{array}{c}\text { Resistance } \\
2600 \mathrm{MHz}\end{array}$ & 46 & 49 & 47 & 46 & 48 \\
\hline $\begin{array}{c}\text { Reactance } \\
2600 \mathrm{MHz}\end{array}$ & -2 & -3 & -3 & -3 & -3 \\
\hline
\end{tabular}

Tab. 2. Input impedance of the proposed antenna in free space and handheld scenarios.

sistance of around $50 \Omega$ (fluctuated between 46 and $50 \Omega$ ) at $700 \mathrm{MHz}$ and $2600 \mathrm{MHz}$. The correspond reactance values of the five cases for the both scenarios at the dual targeted frequencies of $700 / 2600 \mathrm{MHz}$ were varied between -3 and $0 \Omega$. In summary, the antenna response for both free space and hand held scenarios has shown a good impedance matching condition to a $50 \Omega$ load.

\section{Measurement and Simulation Results}

The simulated reflection coefficients of the proposed designs were studied and investigated in the free space and close vicinity to human hand scenarios. The dimension of the hand model surrounding the proposed antenna is assumed as $50 \times 80 \times 110 \mathrm{~mm}^{3}$. The antenna and hand model are illustrated in Fig. 4. For simplicity, the proposed hand model is considered to be a muscle tissue of only a single layer, having a relative permittivity material of 54 and a conductivity of $1.45 \mathrm{~S} \cdot \mathrm{m}^{-1}$ [22], [23].

As depicted in Fig. 4, the hand model takes three typical different configurations of holding the handset, while taking the finger positions into account, i.e., $0^{\circ}$ (Left), $45^{\circ}$ (middle), and $90^{\circ}$ (Right) which are the most common talk positions.

Figure 5 depicts the computed $\mathrm{S}_{11}$ for the balanced antenna (i.e., the antenna with/without balun) in free space scenario and including the human hand effect. Observing Fig. 5, it is obviously seen that the $\left|\mathrm{S}_{11}\right|$ remains below $-10 \mathrm{~dB}$ over the targeted operational dual-band of $700 / 2600 \mathrm{MHz}$ in free space scenarios.

On the other hand, in Fig. 5, the $\mathrm{S}_{11}$ of the antenna in hand effect paradigm of three positions shows approximately a stable performance in term of $\mathrm{S}_{11}$ and in good agreement with the free space scenario. This proves the balanced antenna is ground plane independent and can be a good candidate for practical mobile applications.

For validation purposes of the simulated $\mathrm{S}_{11}$ results of the antenna system without balun, a prototype antenna without the inclusion of balun is shown in Fig. 6(a) and (b). It was initially fabricated based upon on the structure and dimensions as clarified in Fig. 1(b), and then tested. Fig. 7
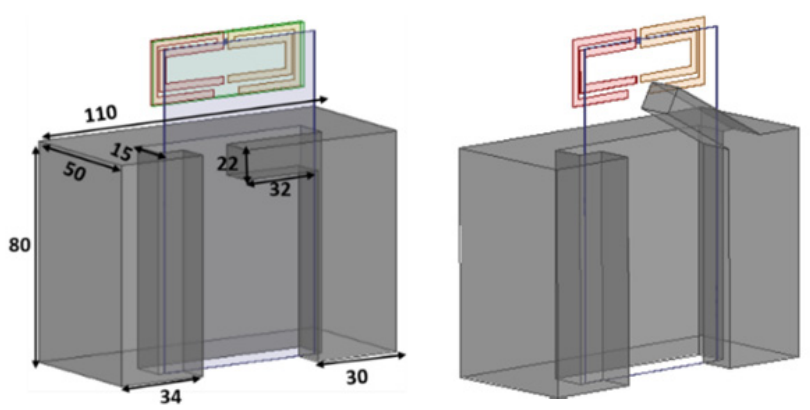

(a)

(b)

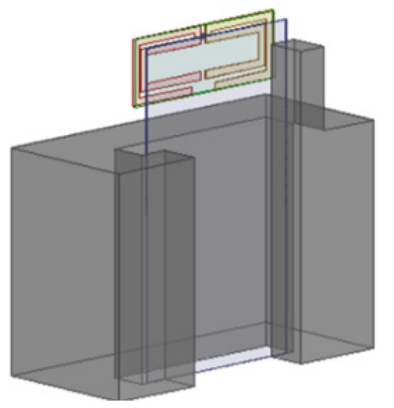

(c)

Fig. 4. Simulated hand model, with finger positions, $0^{\circ}$ (a), $45^{\circ}(\mathrm{b})$, and $90^{\circ}(\mathrm{c})$.

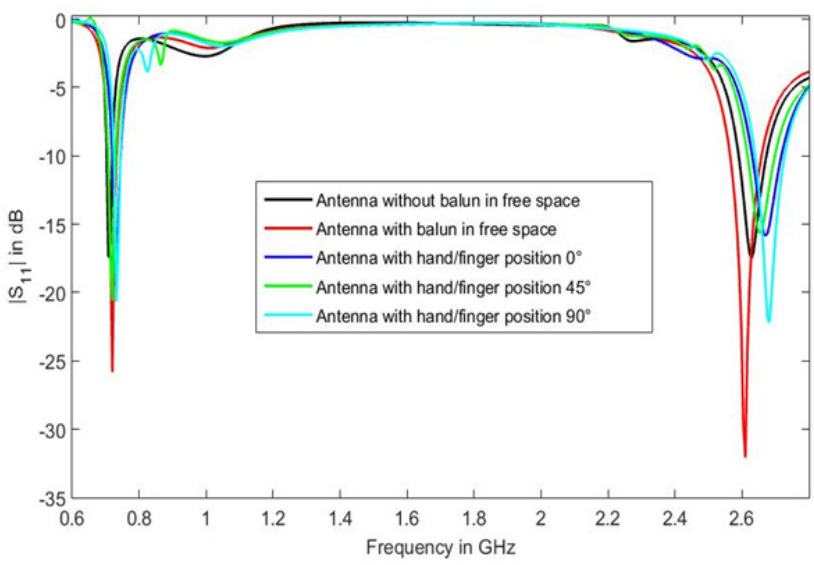

Fig. 5. Simulated reflection coefficients $\left|S_{11}\right|$ of the proposed antennas.

shows the measured $S_{11}$ of the present balanced antennas. The $S_{11}$ of the antenna without balun was achieved by utilizing the method of two port network analyzer whereby the integrated balun was not required. Practically, this was accomplished by direct connection of the balanced antenna two ports into the two inputs ports of a calibrated vector network analyzer. One can clearly observe that the measured results of $S_{11}$ are said to be in fair agreement with the computed results shown in Fig. 5, where the targeted LTE dual-band, 700/2600 MHz was accomplished.

For verification purposes, the full antenna prototype assembly (antenna and balun) has been manufactured and measured as depicted in Fig. 6(c), (d). The measured $S_{11}$ of the antenna with the integrated balun is indicated in Fig. 7. 


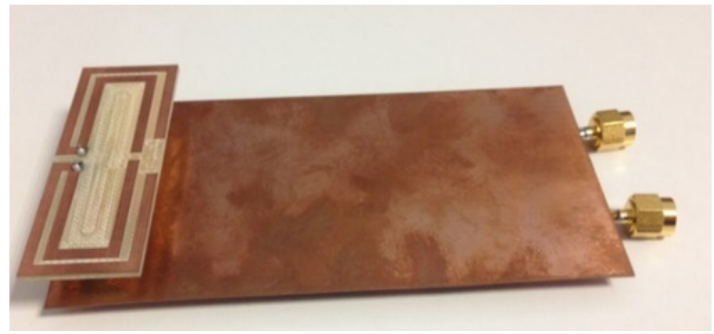

(a)

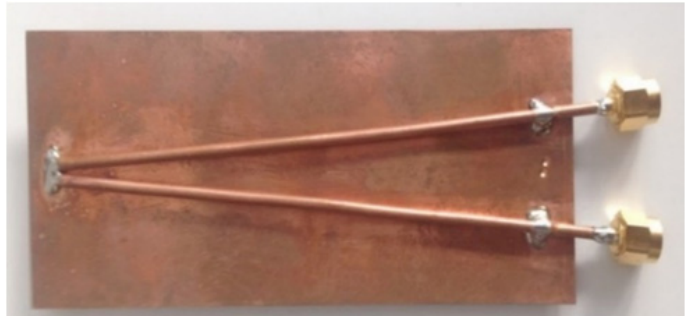

(b)

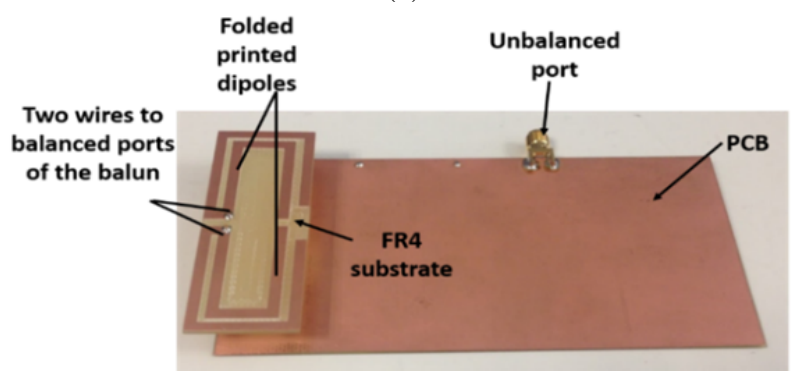

(c)

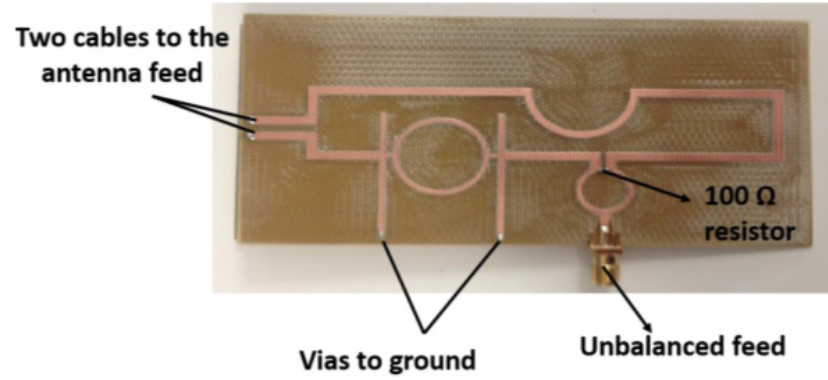

(d)

Fig. 6. The antenna prototypes, (a) 3D without balun, (b) bottom without balun, (c) 3D view with balun, (d) bottom view with balun.

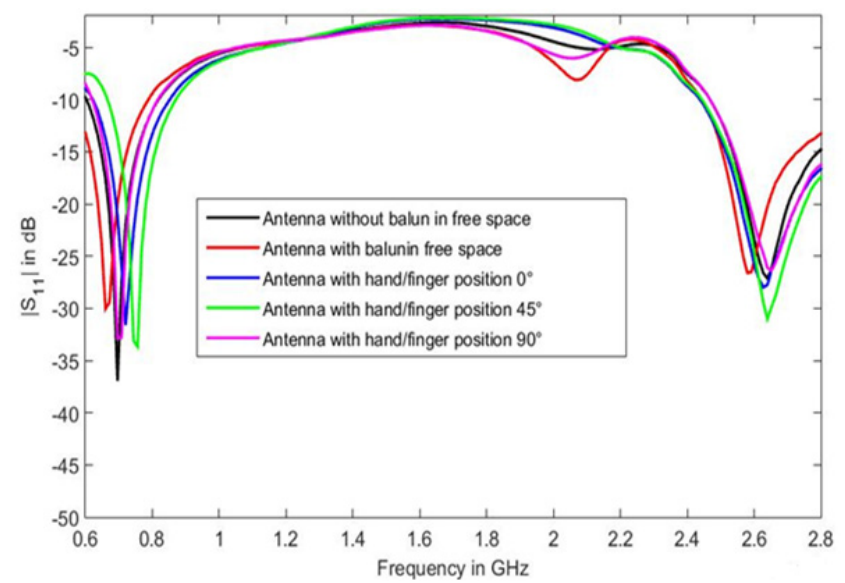

Fig. 7. Measured reflection coefficients $\left|\mathrm{S}_{11}\right|$ of the proposed antennas.
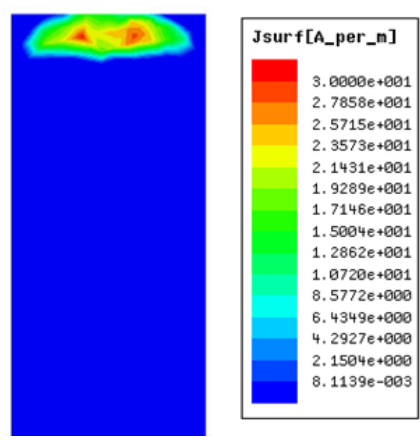

$700 \mathrm{MHz}$

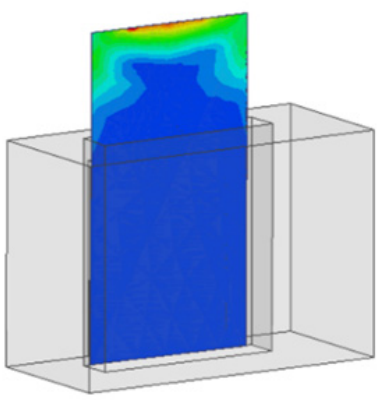

$0^{\circ}$ finger position @ $9700 \mathrm{MHz}$

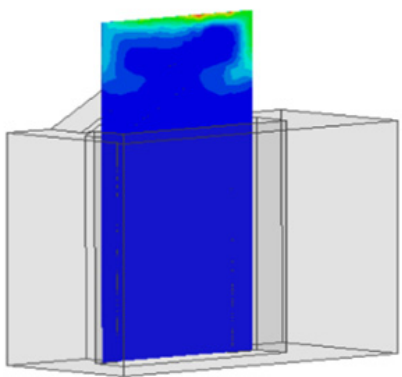

45ำposition@700 MHz

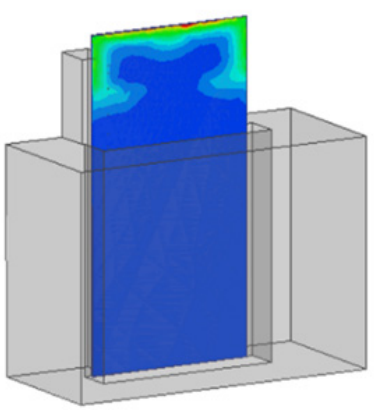

90 position@700 MHz (a)

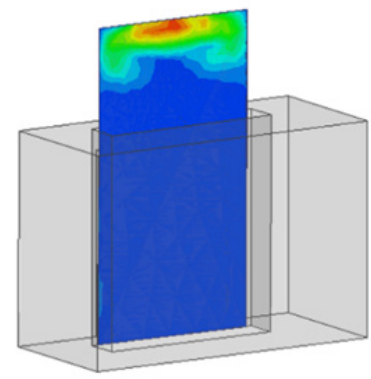

(b) $\quad 0^{\circ}$ finger position @ $2600 \mathrm{MHz}$

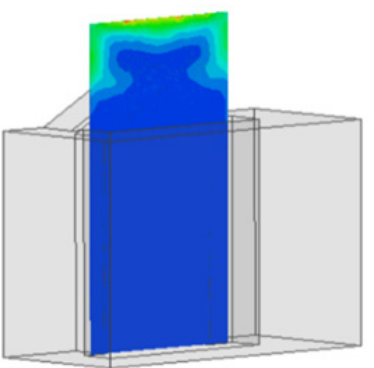

(c)

45position@2600 MHz

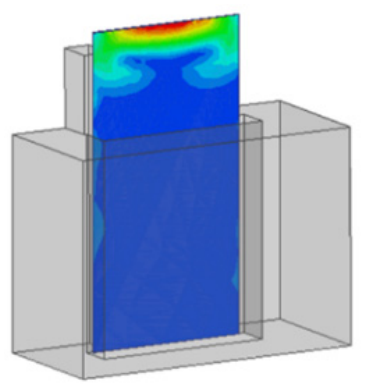

(d) 9090sition@2600 MHz
Fig. 8. Current surface for (a) antenna in free space, (b) antenna with hand finger $0^{\circ}$ position, (c) antenna with hand finger $45^{\circ}$ position, and (d) antenna with hand finger $90^{\circ}$ position.

As can be observed, the measured $\mathrm{S}_{11}$ of the full antenna assembly shows a good result covering the suggested dualband frequency spectrum. The results agree well with the computed results as demonstrated in Fig. 5.

The effect of hand holding scenario on the $S_{11}$ performance of the prototype antennas was also studied and 
investigated in which the ground plane was considered as being held in a hand and positioned in the above-mentioned "talk" positions, shown in Fig. 4. It was noticeable that slight discrepancies occurred between the simulated and measured values of $S_{11}$ in free space within the envisioned operating bands as shown in Fig. 7.

In order to explain how the balanced antenna is ground plane independent, a study of the current intensity of the present design in both free space and hand held scenarios are shown in Fig. 8. The surface current distributions in free space were illustrated over the dual-band of $700 / 2600 \mathrm{MHz}$. It is shown that the surface current induced on the antenna ground plane is strong in the area exactly underneath the feeding point for both frequency bands, while it is neglected over the rest of ground plane as indicated in Fig. 8(a), which is comparable to the results obtained from [16]. It also shows some advantages comparable to the induced current on the ground of the unbalanced antenna in [30].

In the hand model scenario for all finger/talk positions, $0^{\circ}, 45^{\circ}$ and $90^{\circ}$, the major current appears around more or less the similar area in the example of free space, in which the current only exists in the area below the antenna and gradually tapers as we head further away over the whole ground plane as shown in Fig. 8(b), (c) and (d). From the above-mentioned scenarios, this antenna proves the fact that the balanced antenna is ground plane independent. This also suggests that the antenna design has an advantage of being insensitive when it is held by the user's hand.

Figure 9(a) illustrates both the computed and measured gain of full assembly antenna for the $700 / 2600 \mathrm{MHz}$ of LTE frequencies. The computed antenna gain varies from $0.9 \mathrm{dBi}$ and $1.62 \mathrm{dBi}$ over the lower band of $700 \mathrm{MHz}$ and between $3.5 \mathrm{dBi}$ and $4.4 \mathrm{dBi}$ over $2600 \mathrm{MHz}$ band. On the other hand, the measured gain fluctuated between $0.85 \mathrm{dBi}$ and $1.4 \mathrm{dBi}$ over the bandwidth of $700 \mathrm{MHz}$, and from $3.45 \mathrm{dBi}$ to $4.3 \mathrm{dBi}$ over the band of $2600 \mathrm{MHz}$ as detected in Fig. 9(a). These minor variations may be attributed to the introduction of the physical integration of the balun with ground of the device, and the possible existence of errors of the connector pins antenna fabrication.

Figure 9(b) shows the radiation efficiency of antenna assembly. The Wheeler Cap method was adopted here as an easier and practical method to measure the radiation efficiency [31-33]; that is based on the measured antenna input resistances in free space and in the cap. It is observed that the simulated and measured results are in reasonable agreement and consistent with the variations of the gain results achieved in Fig. 9(a). It can also be observed that the simulated efficiency varies from 76 to $81 \%$ over the lower band of $700 \mathrm{MHz}$ and from 81 to $91 \%$ over the $2600 \mathrm{MHz}$; on the other hand, the measured efficiency over the $700 \mathrm{MHz}$ band fluctuates from 80 to $83.6 \%$, while it varies from 85 to $95 \%$ over the higher band of $2600 \mathrm{MHz}$.

The simulated and measured far-field radiation patterns of the proposed antenna assembly (antenna and balun)

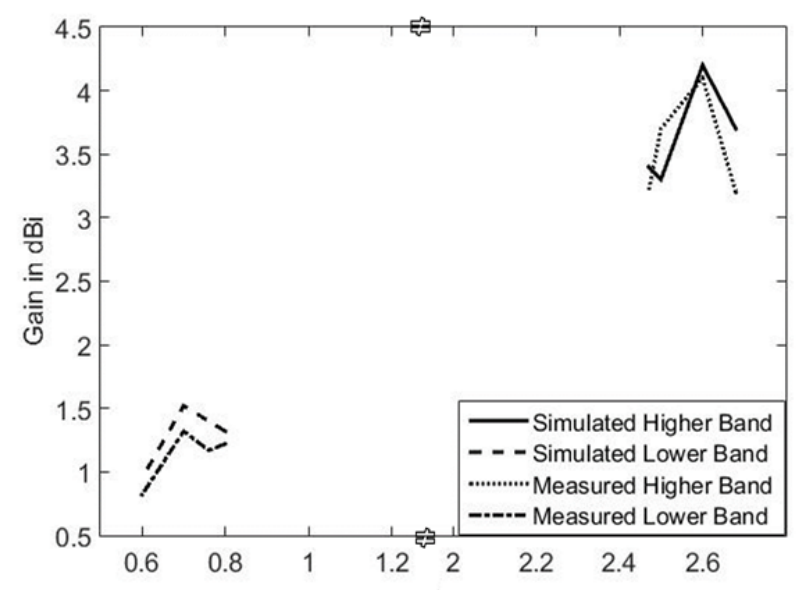

(a)

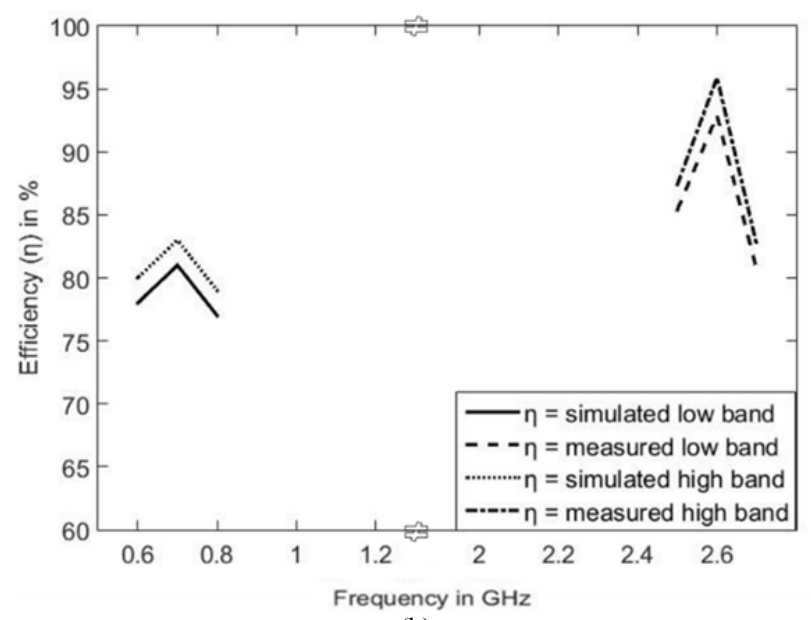

(b)

Fig. 9. (a) Simulated and measured gain of the proposed antenna. (b) Simulated and measured radiation efficiency of the proposed antenna.
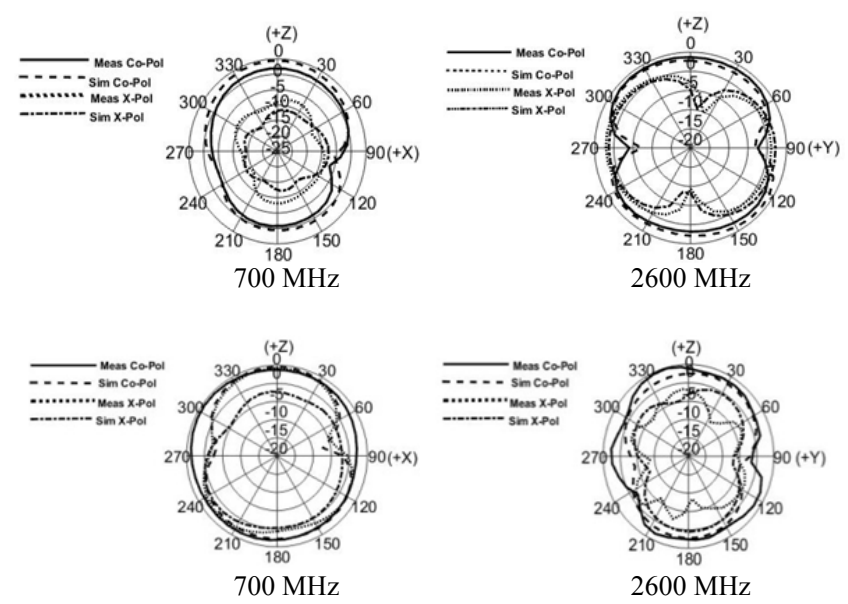

Fig. 10. Normalized antenna radiation patterns for two planes (left: $x z$, right: $y z$ ) at $700 \mathrm{MHz}, 2600 \mathrm{MHz}$, ' $\quad$ measured co-polarization, '- - - simulated copolarization, '------' measured cross-polarization, ‘......' simulated cross-polarization.

were presented in Fig. 10. Two pattern planes cuts at $\mathrm{xz}$ and yz were considered at $700 / 2600 \mathrm{MHz}$, respectively. From Fig. 10, a reasonable agreement was observed be- 
tween computed and measured ones. The accomplished results indicate that the radiation patterns are nearly omnidirectional.

\section{Conclusion}

A balanced antenna covering dual-bands of the LTE standards $698-748 \mathrm{MHz}$ and $2500-2690 \mathrm{MHz}$ has been presented. Computed and measured results of reflection coefficients $\left(\mathrm{S}_{11}\right)$ showed sufficient impedance matching of $\mathrm{S}_{11} \leq-10 \mathrm{~dB}$ including good agreement for free space and hand held with/without balun scenarios. The antenna was demonstrated to exhibit near-omnidirectional radiation over the two operating bands. The surface current of the proposed antenna proves that the currents are diminished over the entire ground plane, except underneath the feeding point where there is improved immunity to the hand-held. This also enhanced the stability of the present mobile antenna to operate at real environment configurations. The antenna could be considered as an attractive candidate for practical applications in mobile phones.

\section{Acknowledgments}

This work is carried out under the grant of the Fundacão para a Ciência e a Tecnologia (FCT - Portugal), with the reference number: SFRH / BPD / 95110 / 2013 and funded by national funds through FCT/MEC (PEstOE/EEI/LA0008/2013 - UID/EEA/50008/2013). The research leading to these results has received funding from the Fundação para a Ciência e Tecnologia and the ENIAC JU (THINGS2DO-GA n. 621221); also, financially supported by the Engineering and Physical Sciences Research Council (EPSRC) in the UK under grant EP/E022936/1.

\section{References}

[1] ANGUERA, J., ANDÚJAR, A., HUYNH, M.C., ORLENIUS, C., PICHER, C., PUENTE, C. Advances in antenna technology for wireless handheld devices. International Journal on Antennas and Propagation, 2013, article ID 838364, 25 p. DOI: $10.1155 / 2013 / 838364$

[2] ABRI, M., BELGACEM, N., BELGACEM, W. New GSM, DCS and GSM/DCS PIFA antenna for wireless networks applications. International Journal of Information Network Security, 2013, vol. 2, no. 4, p. 305-310. ISSN: 2089-3299

[3] CABEDO, A., ANGUERA, J., PICHER, C., RIBO, M., PUENTE, C. Multi-band handset antenna combining PIFA, slots, and ground plane modes. IEEE Transactions on Antennas and Propagation, 2009, vol. 57, no. 9, p. 2526-2533. DOI: 10.1109/TAP.2009.2027039

[4] Gandara, T., PEIXEIRO, C. Compact double U-slotted microstrip patch antenna element for GSM1800, UMTS and HiperLAN2. In IEEE Antennas and Propagation Society Int. Symp. Monterey (California), 2004, p. 1459-1462. DOI: 10.1109/APS.2004.1330463
[5] BRISSOS J., PEIXEIRO, C. Triple-band microstrip patch antenna element for GSM1800, UMTS and HiperLAN2. In Proc. of 2003 IEEE Int. Antennas and Prop. Symp., Columbus (OH, USA), 2003, p. 130-133. DOI: 10.1109 /APS.2003.1220138

[6] FAN, S., T., YIN, Y., Z., HU, W., SONG, K., LI, B. Novel CPWfed printed monopole antenna with an n-shaped slot for dual-band operations. Microwave and Optical Technology Letters, 2012, vol. 54 , no. 1 , p. $240-242$. DOI: $10.1002 /$ mop. 26475

[7] MANOUARE, A. Z., IBNYAICH, S., EL IDRISSI, A., ABDELILAH GHAMMAZ, A. Miniaturized triple wideband CPW-fed patch antenna with a defected ground structure for WLAN/WiMAX applications. Journal of Microwaves, Optoelectronics and Electromagnetic Applications, 2016, vol. 15, no. 3, p. 157-169. DOI: 10.1590/2179-10742016v15i3497

[8] ANG, I., GUO, Y., X., CHIA, Y. W. Compact internal quad-band antenna for mobile phones. Microwave and Optical Technology Letters, 2003, vol. 38, no. 3, p. 217-223. DOI: 10.1002/mop.11019

[9] LEE, C., WONG, K. Planar monopole with a coupling feed and an inductive shorting strip for LTE/GSM/UMTS operation in the mobile phone. IEEE Transactions on Antennas and Propagation, 2010, vol. 58, no. 7, p. 2479-2483. DOI: 10.1109/TAP.2010.2048878

[10] DING-BING LIN, JUI-HUNG CHOU, SON-ON FU, HSUEHJYH LI A compact dual-band printed antenna design for LTE operation in handheld device applications. International Journal of Antennas and Propagation, 2014, 9 p. DOI: 10.1155/2014/897328

[11] ELFERGANI, I., HUSSAINI, S.A., RODRIGUEZ, J., SEE, C. H., ALHAMEED, R. A. Wideband tunable PIFA antenna with loaded slot structure for mobile handset and LTE applications. Radioengineering, 2014, vol. 23, no. 1, p. 345-355.

[12] LIZZI, L., MASSA, A. Dual-band printed fractal monopole antenna for LTE applications. IEEE Antennas and Wireless Propagation Letters, 2011, vol. 10, p. 760-763. DOI: 10.1109/LAWP.2011.2163051

[13] WONG, K. L., LYU, C. A., CHOU, L. C. Small-size multiband planar antenna for LTE700/2300/2500 operation in the tablet computer. Microwave and Optical Technology Letters, 2012, vol. 54, no. 1, p. 81-86. DOI: 10.1002/mop.26507

[14] ABD-ALHAMEED, R. A., EXCELL, P. S., KHALIL, K., ALIAS, R., MUSTAFA, J. SAR and radiation performance of balanced and un-balanced mobile antennas using a hybrid computational electromagnetics formulation. IEE Proceedings - Science, Measurement and Technology, 2004, vol. 151, no. 6, p. $440-444$. DOI: $10.1049 / \mathrm{ip}$-smt:20040855

[15] VAINIKAINEN, P., OLLIKAINEN, J., KIVEKAS, O., KELANDER, K. Resonator-based analysis of the combination of mobile handset antenna and chassis. IEEE Transactions on Antennas and Propagation, 2002, vol. 50, no. 10, p. 1433-1444. DOI: 10.1109 /TAP.2002.802085

[16] ARENAS, J. J., ANGUERA, J., PUENTE, C. Balanced and single-ended handset antennas: free space and human loading comparison. Microwave and Optical Technology Letters, 2009, vol. 51, no. 9, p. 2248-2254. DOI: 10.1002/mop. 24525

[17] ILVONEN, J., KIVEKÄS, O., AZREMI, A. A. H., VALKONEN, R., HOLOPAINEN, J., VAINIKAINEN, P. Isolation improvement method for mobile terminal antennas at lower UHF band. In Proceedings of the $5^{\text {th }}$ European Conference on Antennas and Propagation. Rome (Italy), 2010, p. 1238-1242.

[18] ZHOU, D., ABD-ALHAMEED, R. A., EXCELL, P. S. Bandwidth enhancement of balanced folded loop antenna design for mobile handsets using genetic algorithms. PIERS Online, 2008, vol. 4, no. 1, p. 136-139.

[19] ILVONEN, J., HOLOPAINEN, J., KIVEKÄS, O., VALKONEN, R., ICHELN, VAINIKAINEN, P. Balanced antenna structures of 
mobile terminals. In Proceedings of the $4^{\text {th }}$ European Conference on Antennas and Propagation. Barcelona (Spain), 2010, 5 p.

[20] ELFERGANI, I. T. E., ABD-ALHAMEED, R. A., ALI, N. T. et al. A novel dual band frequency tunable balanced handset antenna for WLAN application. In 18th IEEE International Conference on Electronics, Circuits and Systems, Beirut (Lebanon), 2011, p. 516 to 519. DOI: 10.1109/ICECS.2011.6122326

[21] BEHERA, S. K., PODDAR. D. R., MISHRA, R. K. Design of sequentially fed balanced amplifying antenna for circular polarization. ICTACT Journal on Communication Technology, 2010, vol. 1, no. 4, p. 213-217.

[22] ZHOU, D., ABD-ALHAMEED, R. A., SEE, C. H., EXCELL, P. S. Design of wideband balanced folded-arms dipole antenna for mobile handsets. Electromagnetics, 2009, vol. 29, p. 641-651. DOI: $10.1080 / 02726340903287406$

[23] ZHOU, D., ABD-ALHAMEED, R. A., SEE, C. H., ALHADDAD, A. G., EXCELL, P. S. Compact wideband balanced antenna for mobile handsets. IET Microwaves, Antennas and Propagation, 2010, vol. 4, no. 5, p. 600-608. DOI: 10.1049/iet-map.2009.0153

[24] COLLINS, B. S., KINGSLEY, S. P., IDE, J. M., SAARIO, S. A., SCHLUB, R. W., KEEFE, S. G. O. A multi-band hybrid balanced antenna. In IWAT 2006 IEEE International Workshop on Antenna Technology: Small Antenna and Novel Materials, White Plains (New York), 2006, p. 100-103.

[25] WEN-JUN LU, YA-MING BO, HONG-BO ZHU. Novel planar dual-band balanced antipodal slot-dipole composite antenna with reduced ground plane effect. International Journal of $R F$ and Microwave Computer-Aided Engineering, 2012, vol. 22, no. 3, p. 3319-328. DOI: 10.1002/mmce.20600

[26] JOLANI, F., DADASHZADEH, G. R., NASER-MOGHADASI, M., DADGARPOUR, A. Design and optimization of compact balanced antipodal Vivaldi antenna. Progress In Electromagnetics Research C, 2009, vol. 9, p. 183-192. DOI: 10.2528/PIERC09071510

[27] VIGNESH, N., SATHISH KUMAR, G. A., BRINDHA, R. Design and development of a tapered slot Vivaldi antenna for ultra-wide band application. International Journal of Advanced Research in Computer Science and Software Engineering, 2014, vol. 4, no. 5, p. 174-178. ISSN: $2277128 \mathrm{X}$

[28] ELFERGANI, I. T. E., HUSSAINI, A. S., RODRIGUEZ, J., ALI, A. H., SEE, C. H., ABD-ALHAMEED, R. A. A compact and broadband balun design for LTE applications. Progress In Electromagnetics Research C, 2016, vol. 67, p. 85-95.

[29] HFSS version 14, Ansys Inc, USA, 2013, Available at: http://www.ansys.com/. Accessed on October 10, 2014

[30] YUN-WEN CHI, KIN-LU WONG. Very-small-size printed loop antenna for GSM/DCS/PCS/UMTS operation in the mobile phone. Microwave and Optical Technology Letters, 2009, vol. 51, no. 1, p. $184-192$. DOI: $10.1002 /$ mop. 24008

[31] JOHNSTON, R. W., MCRORY, J. G. An improved small antenna radiation-efficiency measurement. IEEE Antenna and Propagation Society Magazine, 2008, vol. 40, p. 40-48. DOI: $10.1109 / 74.735964$

[32] AGAHI, D., DOMINO, W. Efficiency measurements of portablehandset antennas using the Wheeler cap. Applied Microwave and Wireless, June $2000 . \quad$ Available at: http://www.rfcafe.com/references/articles/EfficiencyMeasurement-Antenna-Wheeler-Cap.htm

[33] HOSUNG CHOO, ROGERS, R., HAO LING. On the Wheeler cap measurement of the efficiency of microstrip antennas. IEEE Transactions on Antennas and Propagation, 2005, vol. 53, no. 7, p. 2328-2332. DOI: 10.1109/TAP.2005.850758

\section{About the Authors ...}

Issa ELFERGANI received his M.Sc. and Ph.D. in Electrical Engineering with Power Electronics (EEPE) from University of Bradford (UK) in 2008 and 2012, with a specialization in tunable antenna design for mobile handset and UWB applications. He is now a Senior Researcher at the Instituto de Telecomunicações - Aveiro (Portugal), working with European research funded projects, whilst serving as technical manager for ENIAC ARTEMOS and EUREKA BENEFIC. He is an IEEE member and member of American Association for Science and Technology (AASCIT). He is a TPC member and reviewer for several IEEE international conferences. He is the author of several journal and conference publications, including one book editorial. His research interests are multi-disciplinary and have a number of cross cutting themes that include research in various antenna designs including MIMO, UWB, balanced and unbalanced mobile phone antennas with the application of theoretical, computational analytical approaches, RF MEMS filter technologies and power amplifiers.

Jonathan RODRIGUEZ received his M.Sc. degree in Electronic and Electrical Engineering and Ph.D from the University of Surrey (UK), in 1998 and 2004, respectively. In 2005, he became a researcher at the Instituto de Telecomunicacoes (IT) - Portugal where he was a member of the Wireless Communications Scientific Area. In 2008, he became a Senior Researcher where he established the 4TELL Research Group (http://www.av.it.pt/4TELL/) targeting next generation mobile networks with key interests on green communications, cooperation, and electronic circuit design. He has served as project coordinator for major international research projects, which includes Eureka LOOP and FP7 C2POWER, whilst serving as technical manager for FP7 COGEU and FP7 SALUS. Since 2009, he became an Invited Assistant Professor at the University of Aveiro (Portugal), and Associate in 2015. He is author of more than 300 scientific works that includes 6 book editorials. His professional affiliations include: Senior Member of the IEEE and Chartered Engineer (CEng) since 2013, and Fellow of the IET (2015).

Fathi ABDUSSALAM was born in Bin-Waleed, Libya. He received the B.Sc. from Al Fatah University, Tripoli, Libya in 1992. After graduation, he had worked at Ministry of Education from 1992 to 2002, and then he joined University of West of England, Bristol, UK to do his M.Sc. degree from 2003 to 2004. He has appointed as lecturer at Higher Institute of Electronics, Tripoli, Libya from 2004 to 2009 and then appointed as a senior lecturer at Azzaytuna University from 2009 to 2014. Since October 2014, he joined the School of Engineering and Informatics at University of Bradford to pursue his Ph.D. research degree. The main objective of his Ph.D. research is to model and analyze complex electromagnetic problems by means of a new hybridized computational technique combining the frequency domain Method of Moments (MoM) and Finite- 
Difference Time-Domain (FDTD) with the optimization process of GA, PSO and FF methods. Fathi has published three conference papers and also contributed to other three since his registration to Bradford University.

Chan H. SEE received the first-class B.Eng. Honors degree in Electronic, Telecommunication and Computer Engineering and a Ph.D. degree from the University of Bradford, U.K., in 2002 and 2007, respectively. Currently, he is a Lecturer in Electrical and Electronic Engineering at Engineering, Sport, and Sciences (ESS) Academic Group, University of Bolton, U.K. He is also appointed as an Honorary Visiting Research Fellow in the Radio Frequency, Antennas, Propagation and Computational Electromagnetics Research Group within the School of Electrical Engineering and Computer Science, University of Bradford. He has published over 100 journal articles and conference papers. He is a co-author for one book and one book chapter. Dr. See was a recipient of two Young Scientist Awards from the International Union of Radio Science (URSI) and Asia-Pacific Radio Science Conference (AP-RASC) in 2008 and 2010, respectively. He is a Chartered Engineer and Member of the Institution of Engineering and Technology (MIET). He has an NVQ level 4 in Management from the Chartered Management Institute.
Raed ABD-ALHAMEED received the B.Sc. and M.Sc. degrees from Basrah University, Basrah, Iraq, in 1982 and 1985, respectively, and the Ph.D. degree from the University of Bradford, West Yorkshire, U.K., in 1997, all in Electrical Engineering. He is a Professor of Electromagnetic and Radio Frequency Engineering at the University of Bradford. He is the senior academic responsible for radio frequency and electromagnetics research in the University of Bradford, for which new antenna design configurations and computational techniques have been developed including several patents. The expertise includes in particular the highly realistic analysis of antenna design process in the presence of large multilayer scatterers, using the Bradford-developed hybrid modeling techniques including MoM, FEM, FDTD and subgridding FDTD methods. He has published over 400 academic journal and conference papers and is co-author of two books and several book chapters. Currently, he is the leader of the Communication Research Group and head of RF and electromagnetics research in the School of Engineering and Informatics, Bradford University. Dr. Abd-Alhameed is a Fellow of the Institution of Engineering and Technology, Fellow of Higher Education Academy, and a Chartered Engineer in the U.K. 